\title{
Investigating Welfare Regime Typologies: Paradoxes, Pitfalls and Potentialities in Comparative Social Work Research
}

\author{
Lennart Nygren*, Sue White** and Ingunn T. Ellingsen*** \\ * Department of Social Work, Umeå University, Sweden \\ E-mail: lennart.nygren@umu.se \\ **Department of Sociological Studies, The University of Sheffield, UK \\ E-mail: sue.white@sheffield.ac.uk \\ ***Ingunn T. Ellingsen, Department of Social Work, University of Stavanger, Norway \\ E-mail: ingunn.t.ellingsen@uis.no
}

The article reviews the relevance and methodological utility of welfare regime typologies for the study of professional sense-making in social work with families. Focus groups were carried out with social workers in European and Latin American countries representing four different policy regimes. A case vignette was used to elicit social workers' descriptions of how welfare policy may influence how they understand their work task and the notion of family. The research team identified methodological challenges of general relevance in similar policy-practice studies. There were paradoxes in terms of homogeneity on the regime level vs. heterogeneity within and between national services. Pitfalls appeared in the selection of regime-typical cases, language/cultural barriers, and in deciding organisational level. The article shows that welfare typologies have potentialities in that they may provide a helpful analytical basis for theoretical and practical reasoning in which syntheses between policy and practice can be explored, discussed and challenged.

Keywords: Welfare regimes, family policy, social work, comparative methodology, vignette study.

\section{Introduction}

Over the last two decades, there has been a growing body of literature outlining arrangements for the delivery of welfare in terms of alternative typologies or regime types. However, these have tended to operate at the macro, or meso, level and have underexplored the everyday activities and discursive practices of welfare state professionals as they interpret policy. Social work, in particular, is concerned with addressing individuals' and families' welfare in the private domain, and is both influenced and challenged by transformations in social policy and social welfare. In this article the authors' attempts to investigate these matters empirically in comparative social work research revealed a number of methodological issues. The article also considers what professional sensemaking can reveal about the operation of typologies at the level of concrete enactment or otherwise. The article focuses particularly on Hantrais' oft-cited analysis (2004) which originally distinguished between four family policy clusters in Europe, reflecting different ways of balancing welfare provisions and family responsibility. 


\section{Welfare regimes and social work - from de-commodification to de-familialisation}

By the construction of regime typologies, scholars have sought to make sense of the overarching configurations of social policy. Operating on a macro level these regime typologies influence micro-level practice in ways that are still under-explored. In 1990, the most influential welfare typology of the time was presented by Esping-Andersen in Three Worlds of Welfare Capitalism (1990). The 'three worlds' differentiates between liberal, conservative and social democratic welfare states. This path breaking typology partly replaced earlier distinctions between selective and universal systems, and elaborated further on residual achievement-performance and institutional-redistributive models (Titmuss, 1974). In spite of the development of alternative and more refined models that add aspects that the Esping-Andersen's original work was criticised for neglecting or downplaying, the original regime typology still remains in use: for example, in epidemiology, where it has been noted that it is used in a 'surprisingly uncritical manner' (Bambra, 2007: 328).

Esping-Andersen's focus on how the welfare state increases individuals' independence from work incomes (de-commodification) meant that the caring functions of welfare states were relatively under-emphasised. Soon after 1990, alternative analytical principles were developed. The search light was shifted to how the welfare state intervened into the state-family relationship, and in this redirection the concept 'de-familialisation' was coined (Lister, 1994). Social care services became increasingly recognised as a significant part of any country's social policy, no matter if they were counted as costs, number of staff or service recipients (Alber, 1995; Sipilä, 1997; Abrahamson, 1999; Rauch, 2007). The de-familialisation concept additionally contained strong arguments in addressing gender issues, not only by looking at the way in which the welfare state was designed to relieve families from some of the caring burdens of children and the elderly, but also as it recognised the role of social care services as major employers of women. In the specific context of comparative social work research, this family oriented conceptual development has been crucial, since social work takes place within statefamily relationships on the street-level. Social workers' professional sense making plays an important role in this intermediate position and includes coping with organisational contexts, complex client needs, emotions and communicative challenges (Helm, 2016).

\section{De-familialisation and familialisation - ambiguous concepts}

A major distinction in the welfare regime debate regarding the de-familialisation concept is the focus on either economic values such as cash benefits and tax deduction, or noneconomic/caring values, such as publicly financed and regulated care services (Yu et al., 2015; Saraceno, 2016). Economic values relate to economic independence for women and to how the welfare system facilitates women's activity as labour force, and by that reduces the economic importance of the family in their lives (Yu et al., 2015). A focus on caring values, on the other hand, regards de-familialisation as 'the extent to which households' caring responsibilities are relaxed either via provisions of welfare measures or via the provision of market services' (Esping-Andersen, 1999).

The ways in which the state regulates caring responsibilities can also vary. Leitner contributes with a distinction between 'welfare regimes that rely on and actively support 
the family as the main source of care provision' and regimes that 'attempt to relieve the family from caring responsibilities' (Leitner, 2003: 357). This distinction covers a range of social services such as elderly care, children's day care and social work with families with complex needs. A possible flaw in this distinction is that it leaves out systems or countries where there is no 'active' support to the family. Leitner's typology solves this dilemma by the creation of three ideal types of familialism - namely explicit, implicit and optional - with various degrees of public support for the caring responsibilities of the family (Leitner, 2003). Explicit familialism means that there is a lack of public and market support and an outspoken policy forcing the family to fulfil caring responsibilities. The implicit variant leads to a similar result but without the explicit articulation. In systems where there are neither political ambitions nor any other alternatives available, the caring function is 'automatically' left to the family. Optional familialism appears in systems that provide services and supportive care policies. Here, the caring function of the family is strengthened and families are given the option to at least partly be unburdened from the responsibility to care (see Saraceno, 2016 for a similar distinction).

How de-familialisation vs familialism/familialisation are understood will obviously be important for the methodology chosen in comparative studies. The frameworks that Esping-Andersen, Leitner and others developed have generated a multitude of comparative analyses of welfare states, not only in Western Europe but also in other parts of the world (Aspalter, 2011). These frameworks may capture policies on the macro and meso levels, but their links with micro-level practice are less investigated. Rush and Keenan suggest that 'professional identities' are embedded in the regime-type, but that social workers have a possible role to challenge regime ideologies (Rush and Keenan, 2013). Additionally, Lyngstad's study of social work educators in Argentina, Chile and Norway showed that professional attitudes were surprisingly equal in spite of the different system contexts (Lyngstad, 2015). Still, little is known about how welfare regime traits generate conditions for professional practice, especially in the state-family intersection.

\section{The family complexity and social work research project (FACSK)}

This article reviews the relevance and utility of welfare typologies for the study of social work professionals' everyday sense-making. In this section, we describe the project Family Complexity and Social Work (FACSK) and its design. This is followed by a discussion of the application of the comparative rationale that emerges out of Hantrais' analysis of family policy clusters in Europe. In this application, paradoxes, pitfalls and potentialities are revealed that appear to have a general relevance in cases where street-level welfare work is linked with regime theory in empirical and comparative research.

In collaboration between eight universities in eight countries, the FACSK project was launched in 2015 (FACSK, 2017). The project responds to gaps in comparative research since it represents a large and often neglected part of social policy - namely, the social services - and, secondly, because it concerns the interplay between complex social problems, professional discretion and family policies. A hypothesis for the FACSK project is that different welfare systems influence social work with families with complex needs in different ways. Hence, it becomes relevant to compare social work not only between countries, but also between types of systems or welfare regimes. Additionally, there is a need for more knowledge on how families with complex needs are encountered, 
particularly since globalisation indicates a mobility of both people and social problems between countries and even continents.

The FACSK project compares family-based social work on a policy, organizational and street-level bureaucratic level in four family policy clusters, as defined by Hantrais in her study of twenty-five EU countries (Hantrais, 2004): de-familialised (Norway and Sweden chosen in the FACSK project), partly de-familialised (Ireland and UK), familialised (Chile and Mexico) and re-familialised (Bulgaria and Lithuania). Covering four major social work service areas (child welfare, addiction, migration and mental health services), the project analyses how social workers across different contexts understand notions of family and how they describe their own practices with families with complex needs.

The project collects data on different levels in the eight countries. National and international databases (e.g. Eurostat, OECD, World Bank) as well as legislation and policy documents provide necessary contextual and structural information. This is complemented with analysis of guidelines and documents detailing the organisational structure of services offered to families with complex needs. Focus group interviews were implemented with social workers in the four service areas with the vignette technique to elicit social workers' understandings and practices when working with complex family cases (Nygren and Oltedal, 2015). The data provide comprehensive information about the understanding of the position of families in relation to social problems, conditions for discretionary social work action, and expected and preferred outcomes of interventions.

The underlying rationale for the FACSK project is that challenges - such as globalisation and its inherent cultural, demographical, ideological and economic transition - place high demands on the social work profession to adapt to conditions that are rapidly changing. Social workers in social care services increasingly face the results of transnational migration such as unaccompanied children, multi-ethnic families and households headed by children or grandparents (Peterson and Bush, 2013). Another challenge is that the idea of a western traditional 'nuclear family', as the model for the design of welfare support systems, is partly being replaced by new and alternative family forms and lifestyles (Kapella et al., 2009; Kuronen, 2010). New patterns in marriages, weakening of the male breadwinner/female care model, decreasing birth rates, divorces, re-marriages etc. contribute to a changed family landscape. This, together with new family forms such as same-sex marriages, LATs ('living apart together'), rainbow-families, Lesbian-Gay-Bi-Trans-Queer (LGBTQ) relationships, as well as increasing numbers of one-person households, many of whom are older, challenge a traditional nuclear family norm (Hantrais, 2004; Ellingsæter and Leira, 2004). On the other hand, this increased complexity does not necessarily imply relativizing or abandoning fundamental family values, e.g. about 'marriage', preferred number of children, etc. Esping-Andersen states that 'recent scholarship has in fact emphasized how key values and preferences regarding family life show little change' (Esping-Andersen, 2016: 19). Welfare states encounter these partly diversified, partly stable trends in different ways, and social workers in the different services areas operate within a welfare mix of different public and non-governmental organisations.

The changing family patterns - in particular, those induced by migration - affect social interventions in several ways. Interventions depend on service workers' competences and levels of discretion when they make crucial decisions regarding clients' eligibility for 
support, service levels and types of services and interventions (Dunér and Nordström, 2006; Evans, 2016). Interventions also rely on how the relationship between the family and the state is perceived and understood. Social workers act in a multitude of welfare state contexts including cultural, institutional, organisational and professional levels, in a cross-fire of 'problem pressure' and 'political pressure' (Rauch, 2007). This complex welfare state environment is influential in how social workers conceptualise 'family' and how they within social service organisations construct and define family members as recipients of their services (Gümüscü et al., 2014). Hence, variations in how social workers approach families with complex needs can be significant not only between countries but also within a country, between geographical regions and even between service areas on the local level.

\section{Family policy clusters and social work research}

A starting point of the FACSK project was to select countries that reflected different welfare systems. The project team found Hantrais' four family policy clusters to be relevant for comparisons on macro, meso and potentially on the micro levels. A unique feature of her model is that it reflects an attempt to:

... capture the complexity of the policy process as a form of social interaction between policy actors with different agendas and interests that change over time, as they react to a variety of socio-economic and cultural pressures, family and household events. (Hantrais, 2004: 199)

The de-familialised, partly de-familialised, familialised, and re-familialised family policy 'regimes' of Hantrais, reflect different ways of balancing of the welfare mix between social service provision and family responsibility (see Table 1). Furthermore, these different family-policy relationships may lead to highly variable consequences in terms of the role of the family, but also in terms of resource distribution between different population groups.

As the table suggests, the different countries are categorised based on family policy design and structure. That said, different understandings of the distribution of statefamily responsibility exists, not only across countries, but also within them, based on factors as gender, religion, age, and socio-economic status (Hantrais, 2004). The level of commitment of state support and the degree of legitimacy of state intervention in family life constitute central features of the clusters/regimes.

Countries belonging to de-familialised regimes are characterised by having an explicit and coherent family policy over time aiming at minimising the individual's reliance on the family through extensive welfare provisions compared to other regimes. On the other side of the scale, there is the familialised regime in which countries hold a non-interventionist approach when it comes to family welfare, which consequently leaves the responsibility for family members' welfare to the family themselves. Welfare systems are considered as fragmented and underdeveloped, resulting in modest measures and support that mainly are means tested and reserved for those most in need. Partly-de-familialised and refamilialised regimes, have elements in common with the other two, respectively. In a partly de-familialised regime, we might expect a greater resistance to intervention in family life, and that welfare services typically hold a strong risk, rather than welfare orientation. A re-familialised regime, on the other hand, is characterised by a political 
Table 1. The family-policy relationship in EU25 member states

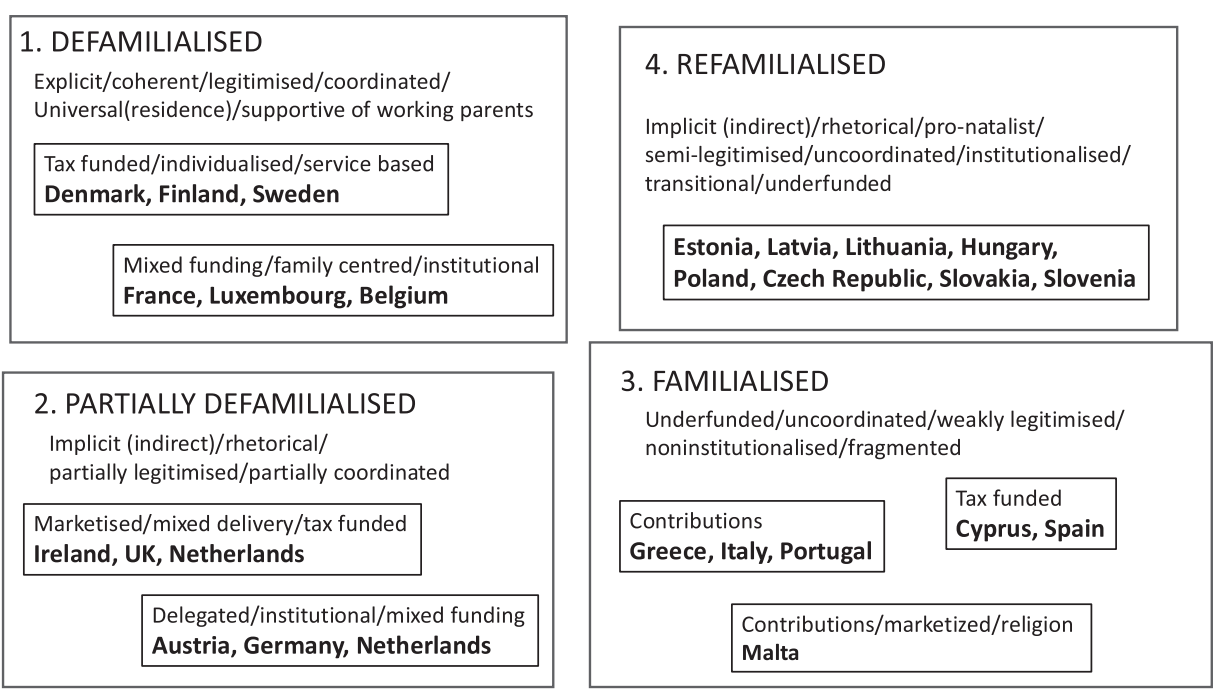

Source: Table adapted from Hantrais (2004: 200).

shift which has led to a transition from the communist era with high state involvement towards a minimalist state and increased market orientation. Consequently, countries in such regimes have experienced a transfer of welfare responsibilities from the state back to the family.

Regime-types may be applicable as a conceptual framework when researching social work and family complexity, in terms of mandate, resources and legitimacy in society. Social workers deal with family complexity in different ways from other welfare professions, as their mandate and professional responsibility concerns both the welfare of the family and the protection of individuals from the family when necessary. In order to understand how social workers address possible tensions and dilemmas, the family policy context as framed in Hantrais' typology becomes relevant. In the FACSK project, the distinctions and categories of Hantrais help to identify relevant focal points in comparative analysis, such as state-family responsibility, legitimacy, institutional structures, as well as how services are coordinated.

The eight countries of the FACSK project have synergies with Hantrais' four regime clusters. They are either de-familialised (Norway and Sweden), partially de-familialised (Ireland and UK), familialised (Chile and Mexico) or re-familialised (Bulgaria and Lithuania). The countries were partly chosen of convenience as the project team had established previous contacts with universities there. Chile and Mexico share many similarities with the countries of the familialised cluster, i.e. southern European countries, even if there are differences. Aspalter (2011: 10) claims that 'Latin America stands out from other ideal-typical welfare regimes by way of its long-term history of 'regulated citizenship' that regulated, rather than addressed, inequality among different sectors and occupational groups'. Aspalter mentions Chile and 'potentially' Mexico as two countries 
of a Latin American welfare state system. In her analysis of welfare regimes in Latin America, Franzoni (2008) identifies both 'regimes' in which the nuclear family plays an important role (e.g. Chile and Mexico), and clusters where extended families are emphasised. Unfortunately, there is no research comparing Latin American countries and European countries along the dimensions Hantrais uses, so we need to be cautious in how we label countries like Chile and Mexico within the framework of Hantrais' typology. We note that these countries still differ from the welfare structures in both the de-familialised and the partly de-familialised cluster portrayed by Hantrais. Compared with European countries, the family in Chile and Mexico hold a great share of the responsibility for the family's welfare. Hence, they were included as exemplars of familialised regimes in the FACSK project.

Lithuania is included in Hantrais' typology, Bulgaria is not. However, both are countries that for many years were behind the iron curtain; Lithuania as a Soviet Union sub-state, and Bulgaria still as a country of its own, but under strong surveillance and control from the Soviet Union. The idea behind the concept re-familialisation is that these countries/states were relatively de-familialised in the decades after World War II, under the influence of the communist economy. There was typically very high work force participation of women and a comprehensive expansion of institutions for children's day care, the care of the elderly and the disabled. After the collapse of the communist bloc many public institutions and the enterprise-based welfare support system for workers and their families were dismantled and caring responsibilities were transferred back to the families and to some extent to NGOs. This had a parallel in an increased influence of traditional, cultural and religious values, and also reinforced by shortage of funding. According to Hantrais:

This does not mean that formal institutional structures for managing family policy are nonexistent, or that they are not legitimised. It does mean they are underfunded, that support for families is often rhetorical rather than practical and that the state is not trusted to deliver good-quality and reliable services. (Hantrais, 2004: 204)

The Eastern European countries have developed in different directions since the early 1990s (Robila, 2012). Some of the countries share strong traditions with the corporatist Christian Democratic welfare regime, with variation in the details. Bulgaria, as a country close to Balkan and southern Europe, has different historical roots than e.g. the Baltic states further north. Related to this, religion can be expected to influence differences in family policy directions: Lithuania as Roman Catholic and Bulgaria as Eastern Orthodox. Still, social policy analysts mean that the move towards re-familialisation is evident: 'in contrast to recent trends in Western Europe, the post-communist countries have explicitly or implicitly tried to persuade women to leave the labor market by pursuing re-familization policies' (Saxonberg and Sirovátka, 2006: 198). Even if the statement is general it indicates that the former countries of the Eastern Bloc struggle with specific obstacles in their development of new family policies. The question is, if these countries are so different in their history, links with Western European countries and in living conditions, may we find that dealing with complex needs will have some fundamentally different solutions? Again, we learn that ideal types are just 'ideal'. For comparative purposes they provide relevant criteria and dimensions to study, but they also produce challenges when they meet everyday professional reasoning. 


\section{Three P's: Paradoxes, pitfalls and potentialities}

In the following, we will address three themes that, based on our research, offer insights to the applicability of a welfare typology on a micro, or practice, level. The first theme concerns possible paradoxes that may challenge the utility of such conceptual frameworks. Secondly, we address pitfalls to which researchers need to be responsive when doing research of this kind. And thirdly, we focus on the potentialities such designs may have. We see these three P's - paradoxes, pitfalls and potentialities - as important considerations when undertaking research combining policy and practice orientations.

\section{Paradoxes}

Typologies may be seen as a classification based on certain features or characteristics. Aspalter (2011) distinguishes between two types of welfare typologies; ideal types that provide a more abstract and long-term perspective, whereas real types seek to articulate a detailed picture to cover the complexity that welfare arrangements comprise. Consequently, real types are more sensitive to shifting realities compared with ideal types. That said, the abstractions upon which ideal welfare typologies draw, risk overlooking important differences within a welfare cluster. Contexts classified within the same ideal type may in reality be very different: for example, when it comes to economic resources (OECD, 2016), and thus also welfare arrangements. A paradox in this is that there may, at least in some areas, be a greater variation within a welfare cluster than between, depending on which issues are the scope of attention. In the FACSK project, Bulgaria and Lithuania are different in many ways in spite of being in the same re-familialised cluster. Also, the FACSK countries are different in terms of the degree and character of decentralisation of services (e.g. Sweden with advancing decentralisation to 290 municipalities, Mexico with thirty-one estados and one Distrito Federal, and the UK that is comprised of four devolved nations).

Furthermore, ideal models are not designed to capture the multi-layered complexities that exist in the 'real world'. In our study, we applied a constructed vignette of a complex family case to focus group interviews to explore how social workers understand the family and how they would work with and intervene in the family. A relevant and paradoxical question is whether it is possible to study differences through a standardised case equally applicable in all eight countries. When the aim is to examine how welfare typologies align with contextual social work with families, it is important to use a vignette that resonates with the practices that are to be examined to avoid hypothetical, and thus ideal, responses. The risk of achieving social desirability responses is a well-known methodological bias, where given answers are congruent with prevailing values or professional expectations (Polit and Beck, 2004), but in a sense these were precisely what we were trying to elicit. The majority of the participants in our research expressed that the case and problematic themes described in the vignette were familiar and relevant to their everyday practice. The vignette had to be subject to rigorous piloting and collaborative drafting and redrafting and prima facie appears to have elicited responses recognisable as 'ordinary business' across the sample.

This suggests that there may be considerable similarity in the moral orientation to family deviance at the 'street level' despite apparently diverse historical, cultural and (prima facie) policy contexts. So, paradoxically, variation within countries and between 
cases in the same regime cluster which informed our method and research design is neutralised, to some extent, by a seemingly global professional ethos.

\section{Pitfalls}

In the FACSK project, the distinctions and categories of Hantrais (2004) were chosen as a starting point since they helped to identify relevant focal points in comparative analysis. During the research process, we were challenged by several pitfalls related to this. A first pitfall concerns case sampling strategies. The FACSK study selected countries that would fit into Hantrais' clustering rationale, and thus represent significant differences in terms of policy contexts. In order to do so, family policy documents and knowledge about institutional structures added important insights in relation to welfare priorities and mandates from a more ideal stand. However, this reveals a second pitfall: language barriers as well as lack of cultural and contextual knowledge constitute significant obstacles in gaining such insights. Without local knowledge, there is a risk of overlooking features that are important for the interpretation of social work practices as embedded in a welfare system. It is therefore crucial to work closely with researchers and stakeholders with local knowledge when 'defining' the welfare context. Furthermore, FACSK co-operation partners were significant door-openers (and translators) both when it came to accessing comparative policy data and research participants in the field.

Other pitfalls concern the selection of welfare services within the countries to elicit knowledge on how welfare typologies align with welfare practices. Particularly when doing cross-contextual research, it is essential that cases subjected to comparison are similar when it comes to the organisational and service levels (Mills et al., 2006). For example, when including child welfare services in the study, such services will obviously be organized differently in the selected countries. Nevertheless, selecting cases from the same institutional level will possibly tailor more valid comparisons than if selected cases represent different parts of these services, e.g. institutional care vs front-line workers dealing with child protection case work. The process to find the adequate level of services may be challenged by the fact that some countries lack state organized services in some fields, where private, or non-profit organisations may be more comparable with state organised services in other countries. When researchers lack contextual knowledge, there is a risk of not selecting the most appropriate cases for comparison. Further, welfare typologies may result in overlooking themes that may be prominent for the context examined, despite not being included in the typologies. That is, the typologies risk operating as a potent lens shaping what is sought and seen. Thus, the researchers need to be open to, and search for, other themes that are important for understanding the relationships between family policy and family practice.

\section{Potentialities}

Despite the paradoxes and pitfalls addressed above, we suggest that regime theories and analytical clusters have considerable utility in comparative research on the micro level. It is important and fruitful to examine critically the everyday activities and discursive practices of welfare state professionals as they interpret policy and how their delivery of welfare aligns with theoretical constructs in terms of typologies and regime types. How family policy (or lack of such policy) comes into action is best studied by researching 
concrete, proximate and specific levels of practice. As Lipsky argues, front-line workers, such as social workers, translate political decisions into practice, and thus create the 'real' policy (Lipsky, 2010), but to understand priorities and actions in practice, welfare policies can add knowledge by revealing underlying causes for their actions.

In relation to Hantrais' cluster analysis, relevant themes may be state legitimacy, the state-family responsibility and character of family services as well as how they are coordinated, in what way market, religion and culture influence family welfare services and how social workers experience the link between policy and practice. When such themes are explored from a front-line worker perspective (in addition to examination of policy documents), they provide rich insights in how policy and practice relate, and furthermore, how welfare typologies interact with welfare practices. For example, social workers from Norway expressed a more explicit reliance on family policy in their practice compared to what was seen in Chile and Mexico, i.e. in relation to children's position as rights holders. Furthermore, in the FACSK vignette, two children went to live with their aunt and uncle. In familialised countries, this was considered a family arrangement, whereas in de-familialised countries, social workers were concerned with formalizing this as a child welfare placement. Having the same point of departure - the vignette - makes it possible to tease out nuances and differences that easily could be missed out using more traditional interview methods. Applying welfare typologies to empirical research may provide a helpful analytical basis for theoretical and practical reasoning in which syntheses between policy and practice can be explored, discussed and challenged. Moreover, comparative research is often based on existing researcher collaborations, which brings its own advantages. That said, applying a conceptual framework for comparative research also provides some 'external' or theoretically driven sampling criteria that may give grounds for a more directed and analytical discussion of inclusion and exclusion choices.

\section{Discussion and conclusions}

Social work with families with complex needs is a unique policy area in terms of the closeness between the service recipient and the public servant (in this case the social worker). In order to study this, it seems more sensitive to use 'family policy regime typologies' rather than welfare state regimes in general. The family policy typology suggested by Hantrais was used in the FACSK project both to identify relevant dimensions for developing an analytical framework for comparing social work in different contexts, and to identify relevant countries for data collection.

The countries chosen for the FACSK project are 'model countries' that function well for comparative purposes within the ideal types of Hantrais four-field table. It is important to emphasise that the eight countries (two from each 'regime') of the study do not give us the chance to draw conclusions in terms of corresponding four types of social work with complex needs. However, they can provide data on systematic conditions for social work practice that can be linked to the four regimes theoretically and contribute with a productive framework to develop new categories from there. Hence, there is a need to make a critical assessment of the concept of de-familialisation. There are two aspects to this. First, the concept de-familialisation in itself is not a singularity in the way it is composed. As has been shown previously, there are different definitions of de-familialisation, most apparent in the distinction between economic de-familialisation as opposed to care-focused de-familialisation (Yu et al., 2015). In terms of social work, 
it can be about both, since social workers usually administrate different types of social assistance and the care of family members in different ages. Also, the different forms of familialism are important to consider. Leitner's three (explicit, implicit and optional) variants certainly produce different conditions for social workers' actions (Leitner, 2003).

Secondly, the de-familialisation concept has limitations in that it explicitly focuses on 'family'. The limitations become visible in alternative concepts that have been put forward. Kröger suggests de-domestication, defined as the 'degree to which social care policies make it possible for people to participate in society and social life outside their homes and families' (Kröger, 2011: 424). Another example is de-genderisation, suggested by Saxonberg, with a focus on policies that promote the elimination of gender roles (Saxonberg, 2013). His concept explicitly sets the focus on how the policies can have an impact on gender roles and power issues within the family, which are obvious dimensions in social work practice that are missing in the application of Hantrais' clustering principles.

Our conclusion is that the dimensions that emerge from Hantrais' four-field typology provide a useful, but relatively blunt, analytical framework for comparisons on the social work practice level. Hantrais' typology is useful as regime constructs are in general: they provide rather stable conceptual frameworks for longitudinal comparisons. They are blunt since they operate on the macro and meso levels, and are less capable of incorporating micro levels of family policy in terms of street-level professionals' understanding, reasoning and discretionary actions. By combining empirical data from social workers focus groups with analysis of policy documents and ideal type regimes, we may elicit additional insights in the relationship between policy and practice when it comes to state versus family responsibilities. Furthermore, there are contextual as well as conceptual challenges in applying typologies in comparative research, in terms of characteristics of countries included and how central concepts in the typologies are to be understood. Paradoxically, whilst the typologies were intended to provide a means to examine differences, and indeed these were found and are the subject of other articles from the FACSK project, there were striking similarities between the regime exemplars of our study in terms of social work sense-making, despite very diverse ranges of potentially relevant factors like material deprivation, everyday safety and security of citizens.

Maybe this should not surprise us, as social work is uniquely mandated to intervene and indeed to police the intimate, relational domain. Thus, there are very real potentialities in using a fictive case, as the one used in the FACSK project, to stimulate thinking as usual' amongst professionals working in different family policy regimes, whilst always remaining critically conscious of the possibilities that such case descriptions, in part, will always construct what they seek to uncover.

\section{Acknowledgements}

The authors are grateful for the funding from NORFACE: The Welfare State Futures Programme.

\section{References}

Abrahamson, P. (1999) 'The welfare modelling business', Social Policy and Administration, 33, 4, 394-415. Alber, J. (1995) 'A framework for the comparative study of social services', Journal of European Social Policy, 5, 2, 131-49. 
Aspalter, C. (2011) 'The development of ideal-typical welfare regime theory', International Social Work, $54,6,735-50$.

Bambra, C. (2007) 'Going beyond The Three Worlds of Welfare Capitalism: regime theory and public health research', Journal of Epidemiology and Community Health, 61, 12, 1098-102.

Dunér, A. and Nordström, M. (2006) 'The discretion and power of street-level bureaucrats: an example from Swedish municipal eldercare', European Journal of Social Work, 9, 4, 425-44.

Ellingsæter, A. L. and Leira, A. (2004) Velferdsstaten og Familien, Oslo: Gyldendal akademisk.

Esping-Andersen, G. (1990) The Three Worlds of Welfare Capitalism, Cambridge: Polity Press.

Esping-Andersen, G. (1999) Social Foundations of Postindustrial Economies, Oxford: Oxford University Press.

Esping-Andersen, G. (2016) Families in the 21st Century, Stockholm: SNS Forlag.

Evans, T. (2016) Professional Discretion in Welfare Services: Beyond Street-Level Bureaucracy, London and New York: Routledge.

FACSK (2017) Family Complexity and Social Work. A Comparative Study of Family-Based Welfare Work in Different Welfare Regimes, Berlin: NORFACE Welfare State Futures, http://bit.ly/1WMDO8T [accessed 02.05.2018].

Franzoni, J. M. (2008) 'Welfare regimes in Latin America: capturing constellations of markets, families, and policies', Latin American Politics and Society, 50, 2, 67-100.

Gümüscü, A., Khoo, E. and Nygren, L. (2014) 'Family as raw material - the deconstructed family in the Swedish social services', Journal of Comparative Social Work, 9, 2, 1-27.

Hantrais, L. (2004) Family Policy Matters: Responding to Family Change in Europe, Bristol: Policy Press.

Helm, D. (2016) 'Sense-making in a social work office: an ethnographic study of safeguarding judgements', Child and Family Social Work, 21, 1, 26-35.

Kapella, O., Rille-Pfeffer, C., Rupp, M. and Schneider, N. F. (2009) Die Vielfalt der Familie, Opladen and Farmington Hills: Barbara Buddrich Publishers.

Kröger, T. (2011) 'Defamilisation, dedomestication and care policy: comparing childcare service provisions of welfare states', International Journal of Sociology and Social Policy 31, 7/8, 424-40.

Kuronen, M. (2010) Research on Families and Family Policies in Europe: State of the Art, Jyväskylä: Family Research Center, Jyväskylä University.

Leitner, S. (2003) 'Varieties of familialism: the caring function of the family in comparative perspective', European Societies 5, 4, 353-75.

Lipsky, M. (2010) Street-Level Bureaucracy: Dilemmas of the Individual in Public Services (30 ${ }^{\text {th }}$ anniversary expanded edn), New York: Russel Sage Foundation.

Lister, R. (1994) "She has other duties': women, citizenship and social security', in S. Baldwin and J. Falkingham (eds.), Social Security and Social Change: New Challenges to the Beveridge Model, New York: Harvest Wheatsheaf, 31-44.

Lyngstad, R. (2015) 'Different welfare system—same values? How social work educators in Norway, Chile and Argentina comprehend core social work and social policy issues', Social Sciences, 4, 1, 239-59.

Mills, M., Van de Bunt, G. G. and De Bruijn, J. (2006) 'Comparative research: persistent problems and promising solutions', International Sociology, 21, 5, 619-31.

Nygren, L. and Oltedal, S. (2015) 'Constructing a vignette for qualitative comparative family research', Journal of Comparative Social Work, 10, 1, 1-14.

OECD (2016) Gross Domestic Product (GDP), https://data.oecd.org/gdp/gross-domestic-product-gdp.htm [accessed 14.10.2017].

Peterson, G. W. and Bush, K. R. (2013) Handbook of Marriage and the Family, New York: Springer.

Polit, D. and Beck, C. T. (2004) Nursing Research: Principles and Methods (7th edn), Philadelphia, PA: Lippincott Williams \& Wilkins.

Rauch, D. (2007) 'Is there really a Scandinavian social service model? A comparison of childcare and elderlycare in six European countries', Acta Sociologica, 50, 3, 249-69.

Robila, M. (2012) 'International perspectives on family policies', Journal of Child and Family Studies, 21, $1,1-3$. 
Rush, M. and Keenan, M. (2013) 'The social politics of social work: anti-oppressive social work dilemmas in twenty-first-century welfare regimes', British Journal of Social Work, 44, 6, 1436-53.

Saraceno, C. (2016) 'Varieties of familialism: comparing four southern European and East Asian welfare regimes', Journal of European Social Policy, 26, 4, 314-26.

Saxonberg, S. (2013) 'From defamilialization to degenderization: toward a new welfare typology', Social Policy and Administration, 47, 1, 26-49.

Saxonberg, S. and Sirovátka, T. (2006) 'Failing family policy in post-communist Central Europe', Journal of Comparative Policy Analysis, 8, 22, 185-202.

Sipilä, J. (1997) Social Care Services: The Key to the Scandinavian Model, Aldershot: Ashgate.

Titmuss, R. (1974) Social Policy. An Introduction, London: Allen and Unwin.

Yu, S., Chau, C. M. and Lee, K. M. (2015) 'Using defamilisation typologies to study the Confucian welfare regime', Journal of International and Comparative Social Policy, 31, 1, 74-93. 